
\title{
28 Research Suare \\ Establishment and Validation of a Clinically Predictive Nomogram Model for Thyroid Carcinoma Patients
}

\section{Ruyi Zhang}

Tianjin Medical University General Hospital

\section{Mei Xu}

Tianjin Medical University General Hospital

\section{Xiangxiang Liu}

Tianjin Medical University General Hospital

\section{Miao Wang}

Tianjin Medical University General Hospital

\section{Qiang Jia}

Tianjin Medical University General Hospital

\section{Shen Wang}

Tianjin Medical University General Hospital

\section{Xiangqian Zheng}

Tianjin Medical University Cancer Institute and Hospital: Tianjin Tumor Hospital

\section{Xianghui He}

Tianjin Medical University General Hospital

\section{Chao Huang}

University of Hull

\section{Yaguang Fan}

Tianjin Medical University General Hospital Tianjin Lung Cancer Institute

\section{Heng Wu}

Tianjin Medical University General Hospital Tianjin Lung Cancer Institute

\section{$\mathrm{KeXu}$}

Tianjin medical university

\section{Dihua Li}

Nankai University Hospital

Zhaowei Meng ( $\nabla$ jamesmencius@163.com )

Tianjin Medical University General Hospital https://orcid.org/0000-0002-4478-878X

\section{Research}


Keywords: Thyroid carcinoma, Nomogram, Prediction model, SEER database, AJCC Cancer Staging Manual

Posted Date: December 10th, 2020

DOl: https://doi.org/10.21203/rs.3.rs-123528/v1

License: (c) (i) This work is licensed under a Creative Commons Attribution 4.0 International License. Read Full License 


\section{Abstract}

\section{Objectives}

To develop a clinically predictive nomogram model which can maximize patients' net benefit in terms of predicting the prognosis of patients with thyroid carcinoma based on the $8^{\text {th }}$ edition of the AJCC Cancer Staging method.

\section{Methods}

We selected 134,962 thyroid carcinoma patients diagnosed between 2004 and 2015 from SEER database with details of the $8^{\text {th }}$ edition of the AJCC Cancer Staging Manual and separated those patients into two datasets randomly. The first dataset, training set, was used to build the nomogram model accounting for $80 \%(94,474$ cases $)$ and the second dataset, validation set, was used for external validation accounting for $20 \%$ (40,488 cases). Then we evaluated its clinical availability by analyzing DCA (Decision Curve Analysis) performance and evaluated its accuracy by calculating AUC, C-index as well as calibration plot.

\section{Results}

Decision curve analysis showed the final prediction model could maximize patients' net benefit. In training set and validation set, Harrell's Concordance Indexes were 0.9450 and 0.9421 respectively. Both sensitivity and specificity of three predicted time points (12 Months,36 Months and 60 Months) of two datasets were all above 0.80 except sensitivity of 60 -month time point of validation set was 0.7662 . AUCs of three predicted timepoints were $0.9562,0.9273$ and 0.9009 respectively for training set. Similarly, those numbers were $0.9645,0.9329$, and 0.8894 respectively for validation set. Calibration plot also showed that the nomogram model had a good calibration.

\section{Conclusion}

The final nomogram model provided with both excellent accuracy and clinical availability and should be able to predict patients' survival probability visually and accurately.

\section{Background}

The incidence of thyroid carcinoma has been rising yearly around the globe and the whole incidence of all thyroid carcinoma patients increased $3 \%$ annually according to Hyeyeun Lim's research article published on JAMA(1). Despite the increasing incidence, mortality has declined gradually due to the development of clinical treatment(2). The prognosis of thyroid carcinoma can be affected by various factors including gender, age, histology type, tumor (T-stage), node ( $\mathrm{N}$-stage), metastasis (M-stage), treatment strategy and so on. The current $8^{\text {th }}$ edition of AJCC Cancer Staging Manual already provided with rather an effective classification, but given these specific stages as well as other factors, how do we predict the actual prognosis within certain years both visually and accurately? Which becomes imperative to build a clinical prediction model to find out which ones of those various factors are the most significant in terms of 
prognosis and explain it to patients with an easily understandable way, nomogram. Nomogram is a statistical tool which can transform a clinically predictive model into a visual graph which produces a numerical probability of a certain clinical event such as death or recurrence(3). Nomogram is even more accurate and applicable in clinical prediction compared to conventional staging and has been widely used in medicine field, especially in oncology(4). Unfortunately, there hasn't been any effectively predictive nomogram models taking all useful factors (factors can maximize patients' net benefit) into consideration for thyroid carcinoma patients based on huge population data(5-7), whereas our study presented such accurate tool timely.

\section{Materials And Methods}

\section{Study population}

The design of this model was based on patients from Surveillance, Epidemiology, and End Results (SEER) Program supported by the Surveillance Research Program (SRP) in NCl's Division of Cancer Control and Population Sciences (DCCPS). As shown in Table 1, a total of 134,962 patients were diagnosed with thyroid carcinoma from 2004 to 2015, 32,783 of which were male and 102,179 of which were female. Each variable was stratified by gender and its percentages did not contain N/A cases. T0 was excluded from our study because there were only 290 cases identified and didn't have statistical value. Also, TX, T NOS, NX, N NOS, as well as MX were excluded because they didn't have significance for our study. All results and graphs were produced by R Project 3.6.1, Empower Stats 2.20 and IBM SPSS statistics 23.

\section{Variable selection and univariate analysis}

Gender is considered a risk factor which affects the outcome of thyroid carcinoma and it's well-known to us that female has a better chance of survival than male. The impact of gender has always been controversial as some researchers claim that there is a significant statistical difference in terms of survival between male and female(8), yet others say there is indeed a difference when gender is considered as an independent factor and this so-called significant difference will vanish in multivariate analysis(9). That's why, in our study, we analyzed gender influence in both univariate and multivariate model to explore whether this factor can be an independent predictive variable.

Age as a risk factor is introduced into the $8^{\text {th }}$ edition of the AJCC Cancer Staging Manual and is divided into two groups using 55 years old as a threshold instead of the previous 45 years old in the $7^{\text {th }}$ edition(10). This is very important for patients between $45-55$ years old in the purpose of preventing overstaging in low-risk patients and preventing over-aggressive treatment(11).

Among the four main types of thyroid carcinoma, ATC (Anaplastic thyroid carcinoma) is the one with the rarest incidence and accounts for the majority of deaths from thyroid carcinoma despite its rare morbidity due to its malignant character(12). By contrast, PTC (Papillary thyroid carcinoma) is the commonest type with an excellent prognosis (survival rates of $>95 \%$ at 25 years) and can be especially found among women(13). FTC (Follicular thyroid carcinoma) is another less common type of well-differentiated thyroid 
carcinoma. MTC is an aggressive form of thyroid carcinoma causing about $8 \%$ to $15 \%$ of all thyroid cancer-related deaths(14). Different histology comes with a different prognosis and because of this difference, it's important to put histology variable into univariate analysis to see how they contribute.

There are many changes in the latest $8^{\text {th }}$ edition of the AJCC cancer staging manual: For PTC, FTC and ATC, T3a is a new category and refers to a tumor $>4 \mathrm{~cm}$ in greatest dimension limited to the thyroid gland (this number is $\geq 4 \mathrm{~cm}$ for MTC), T3b is a new category and is defined as a tumor of any size with gross extrathyroidal extension invading only strap muscles (sternohyoid, sternothyroid, thyrohyoid, or omohyoid muscles), as well as level VII lymph nodes were added to N1 a and MTC has been removed from above becoming a new chapter(15). Because of these changes and the latest version of SEER program didn't provide with details of $8^{\text {th }}$ edition, we converted all the patients selected from $6^{\text {th }}$ edition and $7^{\text {th }}$ edition to $8^{\text {th }}$ edition using IBM SPSS for further analysis.

There are mainly five strategies for DTC (Differentiated thyroid carcinoma) patients treatment including: TSH-suppressive therapy, ${ }^{131}$ I therapy, locoregional and adjuvant/adjunctive treatments (like surgery, radiotherapy, thermal/ethanol or cryoablation or embolization), targeted treatment, redifferentiation and other novel therapeutic approaches(16). All ATC patients fail to uptake iodine and are usually resistant to chemotherapy and the preferred strategy is surgery according to the American Thyroid Association (ATA) guidelines(17). As for patients with unresectable primary tumors, the role of surgery is to establish advantageous conditions to further perform palliative protocols(18). Different strategy should produce different prognosis, so we selected three factors including chemotherapy, ${ }^{131}$ I therapy, and surgical method to explore whether these treatment factors can be used as predictive variables.

All those factors above are associated with prognosis of thyroid carcinoma, so we evaluated influences of these factors by putting them into univariate COX regression model and Kaplan-Meier model.

\section{Multivariate analysis and variable screening}

To find out whether a certain variable still shows significantly statistical difference when other variables exist at the same time, we had to put all these variables into a COX regression model for multivariate analysis. COX model, also known as proportional hazards model, is widely used in medical researches to analyze the influences of multiple risk factors(19). In this step, we discarded those variables which may show significantly statistical difference in univariate analysis but may not in multivariate COX analysis. This COX model could produce several coefficients which later was used to develop a nomogram model.

\section{Test of clinical use}

Conventionally, there are mainly several diagnostic test indicators such as sensitivity, specificity and AUC as demonstrated below and these indicators only measure the diagnostic accuracy of the prediction model, but fail to consider the clinical availability of it. DCA (Decision Curve Analysis) is such a novel tool which can be used to evaluate whether a prediction model has clinical usage by calculating the value of net benefit within certain range of threshold probabilities $(20,21)$. This net benefit is produced by 
comparing the difference between expected benefit and expected harm related to each proposed testing and treatment method(22). We used this tool to analyze the clinical availability of the final model.

\section{Design and validation of predictive nomogram model}

Based on cox model final results (coefficients of all variables), we then used an R package called RMS to plot a nomogram to estimate 1-year, 3-year and 5-year survival probability with a line segment(23). In order to test the accuracy of this model, we divided all patients into two groups randomly- The first dataset, training set, was used to build the nomogram model accounting for $80 \%$ ( 94,474 cases) and the second dataset, validation set, was used for external validation accounting for $20 \%$ (40,488 cases). The accuracy of this nomogram model can be evaluated by AUC, C-index (Harrell's Concordance Index), and calibration plot $(24,25)$. We used this model to predict patients' survival probability of 1-year, 3-year and 5year time point and calculated the AUCs, C-indexes as well as calibration performances of each time point of each dataset.

\section{Results}

\section{Univariate analysis}

In univariate COX regression and Kaplan-Meier analysis (Table 2), all variables showed significantly statistical differences ( $\mathrm{P}$ value $<0.0001$ ) although TT (total thyroidectomy) presented a slightly bigger $\mathrm{P}$ value $(P$ value $=0.0048)$. The HR (Hazard Ratio) value of female group was $0.38(95 \% \mathrm{Cl}: 0.36,0.41)$ compared to male group. Age group 2 had both greater HR value $(10.55,95 \% \mathrm{Cl}: 9.66,11.53)$ and events (dead attributable to this cancer diagnosis, 2,911 cases) compared to age group 1 (586 cases). Among these four forms of thyroid carcinoma, ATC had the greatest HR value $(237.99,95 \%$ Cl: $216.38,261.75)$, coefficient (5.47) as well as events (736 cases) with an MST (median survival time) of 3 months. Among all T-stage groups, T4b had the greatest HR value $(233.66,95 \% \mathrm{Cl}: 190.75,286.23)$, coefficient (5.45) with an MST of 79 months. Among N-stage groups, N1b had the greatest HR value (11.87, 95\% Cl: 10.36, 13.60) and coefficient (2.47) and didn't reach the MST. Between M0 and M1 groups, M1 had the greatest HR value $(58.97,95 \% \mathrm{Cl}: 54.94,63.29)$ and coefficient $(4.08)$ with an MST of 28 months. Patients with chemotherapy resulted in bigger HR value $(44.93,95 \% \mathrm{Cl}: 41.25,48.93)$ and bigger coefficient (3.81) with an MST of 12 months compared to N/U (No, Unknown). Patients with ${ }^{131}$ I therapy resulted in lower HR value $(0.49,95 \% \mathrm{Cl}: 0.45,0.53)$ and lower coefficient $(-0.72)$ compared to $\mathrm{N} / \mathrm{U}$. As for surgical method group, the HR value and coefficient of S/N T (subtotal or near total thyroidectomy) were $2.47(95 \% \mathrm{Cl}$ : $1.91,3.19)$ and 0.90 compared to LO (Lobectomy only) and those numbers were 1.33 (95\% Cl: 1.09, 1.63) and 0.29 for TT (Total thyroidectomy).

\section{Multivariate analysis}

In multivariate COX regression analysis (Table 3), all variables of the final model 3 presented significantly statistical differences after variable screening procedures of model 1 and model 2. Of all levels of all variables, T4b had the greatest coefficient (3.27) and HR value (26.36, 95\% Cl: 19.51, 35.61). With these 
coefficients, we experimentally developed two predictive models including model 3 and model 3 without ${ }^{131}$ I therapy for further comparison.

\section{Test of clinical use}

Figure 1 is a comparison between model 3 and model 3 without ${ }^{131}$ I therapy. It showed that using either one of these two models to predict patient's prognosis would obtain more net benefit compared to treatall-patients group or treat-none-patients group. However, within most of the threshold probability range, DCA indicated that model 3 without ${ }^{131}$ I therapy would definitely add even a lot more net benefit when comparing model 3 in terms of predicting patients' prognosis. Both prediction models were absolutely clinically useful, but model 3 without ${ }^{131}$ I therapy was the best ideal one to maximize patients' net benefit.

\section{Design of nomogram model}

We transformed model 3 without ${ }^{131}$ I therapy into a nomogram model (Figure 2). Each level of each variable was scored by its contribution to the final outcome and with these scores of each variable we could calculate the total points to evaluate patients' risk of death or probability of survival within certain years.

\section{Validation of nomogram model}

In training set and validation set, C-indexes were 0.9450 (95\% Cl: $0.9378,0.9522)$ and 0.9421 (95\% Cl: $0.9314,0.9528)$ respectively. Both sensitivity and specificity of all predicted time points ( 12 Months, 36 Months and 60 Months) of two datasets were all above 0.80 except sensitivity of 60-month time point of validation set was 0.7662 . AUCs of three predicted time points were $0.9562,0.9273$ and 0.9009 respectively for training set. Similarly, those numbers were $0.9645,0.9329$ and 0.8894 respectively for validation set (Table 4, Figure 3 ). Figure 4 showed the calibration curve of each time point, $\mathrm{X}$-axis stood for predicted survival probability and $Y$-axis stood for observed survival probability. The gray line was the ideal calibration segment. In Figure 4, all calibration curves twisted around the gray ideal one.

\section{Discussion}

In this study, we developed a nomogram model using univariate and multivariate analysis method based on 134,962 thyroid carcinoma patients' clinical data. The final nomogram model consisted of 6 variables including gender, age, histology type, T-stage, $\mathrm{N}$-stage as well as M-stage. Its accuracy had been demonstrated by C-index, AUC as well as calibration plot and its clinical availability had been demonstrated by DCA. Our study showed that this nomogram model could be used to predict patients' survival probability.

The final nomogram was developed after going through 4 procedures. Firstly, we selected several positive risk factors which can worsen the final outcome such as age, gender and TNM classification and several negative treatment factors such as ${ }^{131}$ I therapy and chemotherapy which can cure or alleviate the final 
outcome. We could then find out whether these negative treatment factors can be used to predict patients' survival probability. Secondly, we screened out variables by putting them into univariate and multivariate analysis. In univariate analysis, all variables showed significantly statistical differences, so we then put them into multivariate analysis to see how they perform. In model 1, surgical method showed no statistical difference (P value S/N T: 0.24, TT: 0.89), which means surgical method had no effect on prognosis generally, so we removed this variable to obtain model 2 . Without surgical method, chemotherapy showed no statistical difference (P value: 0.23 ). Likewise, we excluded chemotherapy to obtain model 3. In model 3 , all variables showed significantly statistical differences. Thirdly, we used DCA to test its clinical usage and we found out that although model 3 and model 3 without ${ }^{131}$ I therapy were both clinically useful, DCA suggested that model 3 without ${ }^{131}$ I therapy was the best ideal one to maximize patients' net benefit in terms of predicting prognosis alone. This result also suggested that using negative treatment factors to predict patients' prognosis is inappropriate. Though ${ }^{131}$ I therapy is considered to be an effective strategy, it's often used to treat DTC and is not suitable to treat other types of thyroid carcinoma $(26,27)$. Because of this, the final nomogram model did not contain ${ }^{131}$ I therapy. Lastly, we used several indicators including C-index, AUC as well as calibration plot to evaluate its accuracy.

In univariate analysis, the HR value of female group was 0.38 compared to male group and this figure increased to 0.77 in multivariate analysis but still showed significantly statistical difference. This result indicated that gender is an applicable factor to develop a predictive model. Hwang, S.H., et al.'s study also manifested that male gender is indeed a significant independent risk factor(28). Only few studies

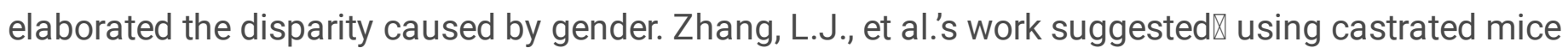
model, that this difference is likely to be caused by the role of testosterone which reduces the tumorsuppressive effects of Glipr1 and Sfrp 1 by restraining the secretion of CCL5 during cancer progression, a chemokine which activates and reinforces the antineoplastic immunologic function(29). Consequently, male patients often present advanced thyroid carcinoma(30). Several reports also manifested the higher rate of malignant thyroid nodules among male patients(31-33).

Our study showed that age variable presented a pretty higher coefficient and HR value whether in univariate analysis or multivariate analysis and the figure was even higher than T3a stage in multivariate analysis. This suggested that age is an important prognostic indicator for thyroid carcinoma. Younger patients often achieve a much better prognosis compared to older ones even they have the same degree of disease. The mechanism behind this is still unclear. One hypothesis is that older patients have a much higher level of thyroid stimulating hormone which may stimulate the mutations of TSHR (Thyroid stimulating hormone receptor) causing high rate of malignant character through two pathways including the cAMP pathway via $G_{a s}$ and the Ras dependent MAPK pathway via $G_{\beta \gamma}$ and $P_{3} 3 K_{\gamma}(34-36)$. Another hypothesis is that older age damages an individual's immune system like lymphocyte which can limit the invasion of malignant nodules(37).

The $8^{\text {th }}$ edition of AJCC cancer staging manual subdivided NO stage into two stages--NOa and NOb. The definition of $\mathrm{NOa}$ is one or more cytologically or histologically confirmed benign lymph nodes and the definition of $\mathrm{NOb}$ is no radiologic or clinical evidence of locoregional lymph node metastasis(38). In our 
analysis, our result suggested that NOb patients indeed have a higher HR value compared to N0a (2.06, 95\% Cl: 1.81, 2.35 in univariate analysis, 1.53, 95\% Cl: 1.26, 1.85 in multivariate analysis) (Table2 and Table3). This also demonstrated the advantage of current $8^{\text {th }}$ staging method which can provide clinicians with the most specific detail to treat patients with different stages.

Figure 2 also demonstrated an example we had predicted with this model. The patient's clinical stage group was $₫ \mathrm{C}$ and his 1 -year survival probability was about $30 \%$. This predicted result was relatively close to Rao, S.N., et al.'s study (39\% survival at 1 year)(39).

There are two limitations to our study. First, serological indexes were not considered currently because it's not available in the SEER database. For example, serum thyroglobulin is a necessary index which can monitor recurrence or progression of DTC and further guide the adjustment of follow-up plan and treatment strategy(40). Second, T0 stage was excluded due to the lack of cases and this made contrast less accurate compared to $\mathrm{N}$-stages or M-stages. Further study will be required.

\section{Conclusion}

Generally, our study presented a nomogram model which was not only accurate but also clinically useful than conventional predictive model in terms of predicting the outcome of thyroid carcinoma. This nomogram model is also suitable to apply in other fields especially in oncology and is worth promoting vigorously.

\section{Abbreviations}

N/U, No/Unknown;

LO, Lobectomy only;

S/N T, Subtotal or near total thyroidectomy;

TT, Total thyroidectomy;

MST, Median survival time;

\section{Declarations}

\section{Ethics approval and consent to participate}

Not applicable

\section{Consent for publication}

Not applicable 
Availability of data and materials

The datasets [GENERATED/ANALYZED] for this study can be found in the [ Surveillance, Epidemiology, and End Results (SEER) Program] [https://seer.cancer.gov/]. Also, The datasets are available from the corresponding author on reasonable request.

\section{Competing interests}

The authors declare that they have no competing interests.

\section{Funding}

Data collection of this research was funded by the National Natural Science Foundation of China grants (\#81571709 and \#81971650 to Zhaowei Meng, \#81872169 to Xiangqian Zheng) and the design of this research was funded by the Key Project of Tianjin Science and Technology Committee Foundation grant (\#16JCZDJC34300 to Zhaowei Meng), Tianjin Science and Technology Committee Foundation grants (\#17JCYBJC25400 to Yaguang Fan, \#19JCYBJC27400 to Xiangqian Zheng), Tianjin Medical University General Hospital New Century Excellent Talent Program (to Zhaowei Meng), Young and Middle-aged Innovative Talent Training Program from Tianjin Education Committee (to Zhaowei Meng) and Talent Fostering Program (the 131 Project) from Tianjin Education Committee and Tianjin Human Resources and Social Security Bureau (to Zhaowei Meng).

\section{Author's contributions}

$\mathrm{RZ}, \mathrm{ZM}$ and $\mathrm{KX}$ contributed to the conception and design of the study. RZ wrote the manuscript. XL, MW, $\mathrm{QJ}, \mathrm{SW}, \mathrm{XZ}, \mathrm{XH}, \mathrm{CH}, \mathrm{YF}$ and $\mathrm{HW}$ revised the manuscript. All authors contributed to manuscript revision, read, approved the submitted version and agreed to be accountable for all aspects of the research in ensuring the accuracy of this study. All authors have given consent to the publication of this manuscript.

\section{Acknowledgments:}

The authors thank Dr Zhaowei Meng, who has always been a source of encouragement and inspiration.

\section{References}

1. Lim H, Devesa SS, Sosa JA, Check D, Kitahara CM. Trends in Thyroid Cancer Incidence and Mortality in the United States, 1974-2013. JAMA. 2017;317(13):1338-48.

2. La Vecchia C, Malvezzi M, Bosetti C, Garavello W, Bertuccio P, Levi F, et al. Thyroid cancer mortality and incidence: a global overview. Int J Cancer. 2015;136(9):2187-95.

3. lasonos A, Schrag D, Raj GV, Panageas KS. How to build and interpret a nomogram for cancer prognosis. J Clin Oncol. 2008;26(8):1364-70. 
4. Balachandran VP, Gonen M, Smith JJ, DeMatteo RP. Nomograms in oncology: more than meets the eye. Lancet Oncol. 2015;16(4):e173-e80.

5. Ho AS, Wang L, Palmer FL, Yu C, Toset A, Patel S, et al. Postoperative Nomogram for Predicting Cancer-Specific Mortality in Medullary Thyroid Cancer. Annals of surgical oncology. 2015;22(8):27006.

6. Kim SK, Lee JH, Woo JW, Park I, Choe JH, Kim JH, et al. Prediction Table and Nomogram as Tools for Diagnosis of Papillary Thyroid Carcinoma: Combined Analysis of Ultrasonography, Fine-Needle Aspiration Biopsy, and BRAF V600E Mutation. Medicine. 2015;94(21):e760.

7. Liu G, Liu Q, Sun SR. Nomograms for estimating survival in patients with papillary thyroid cancer after surgery. Cancer management and research. 2019;11:3535-44.

8. Ellison LF. Differences in cancer survival in Canada by sex. Health Rep. 2016;27(4):19-27.

9. Jonklaas J, Nogueras-Gonzalez G, Munsell M, Litofsky D, Ain KB, Bigos ST, et al. The impact of age and gender on papillary thyroid cancer survival. J Clin Endocrinol Metab. 2012;97(6):E878-E87.

10. Perrier ND, Brierley JD, Tuttle RM. Differentiated and anaplastic thyroid carcinoma: Major changes in the American Joint Committee on Cancer eighth edition cancer staging manual. CA Cancer J Clin. 2018;68(1):55-63.

11. Kim M, Kim YN, Kim WG, Park S, Kwon H, Jeon MJ, et al. Optimal cut-off age in the TNM Staging system of differentiated thyroid cancer: is 55 years better than 45 years? Clin Endocrinol (Oxf). 2017;86(3):438-43.

12. Molinaro E, Romei C, Biagini A, Sabini E, Agate L, Mazzeo S, et al. Anaplastic thyroid carcinoma: from clinicopathology to genetics and advanced therapies. Nat Rev Endocrinol. 2017;13(11):644-60.

13. LiVolsi VA. Papillary thyroid carcinoma: an update. Mod Pathol. 2011;24 Suppl 2:S1-S9.

14. Pusztaszeri MP, Bongiovanni M, Faquin WC. Update on the cytologic and molecular features of medullary thyroid carcinoma. Adv Anat Pathol. 2014;21(1):26-35.

15. Metere A, Aceti V, Giacomelli L. The surgical management of locally advanced well-differentiated thyroid carcinoma: changes over the years according to the AJCC 8th edition Cancer Staging Manual. Thyroid Res. 2019;12:10-.

16. KreissI MC, Janssen MJR, Nagarajah J. Current Treatment Strategies in Metastasized Differentiated Thyroid Cancer. J Nucl Med. 2019;60(1):9-15.

17. Saini S, Tulla K, Maker AV, Burman KD, Prabhakar BS. Therapeutic advances in anaplastic thyroid cancer: a current perspective. Mol Cancer. 2018;17(1):154-.

18. Carling T, Udelsman R. Thyroid cancer. Annu Rev Med. 2014;65:125-37.

19. He X, Liu C, Chen Y, He J, Dong Y. Overweight Without Central Obesity, Cardiovascular Risk, and AllCause Mortality. Mayo Clin Proc. 2018;93(6):709-20.

20. Stanhiser J, Chagin K, Jelovsek JE. A model to predict risk of blood transfusion after gynecologic surgery. Am J Obstet Gynecol. 2017;216(5):506.e1-.e14. 
21. Vickers AJ, Elkin EB. Decision curve analysis: a novel method for evaluating prediction models. Med Decis Making. 2006;26(6):565-74.

22. Fitzgerald M, Saville BR, Lewis RJ. Decision curve analysis. JAMA. 2015;313(4):409-10.

23. Kattan MW, Eastham JA, Stapleton AM, Wheeler TM, Scardino PT. A preoperative nomogram for disease recurrence following radical prostatectomy for prostate cancer. J Natl Cancer Inst. 1998;90(10):766-71.

24. Wang S, Yang L, Ci B, Maclean M, Gerber DE, Xiao G, et al. Development and Validation of a Nomogram Prognostic Model for SCLC Patients. J Thorac Oncol. 2018;13(9):1338-48.

25. Huang Y-Q, Liang C-H, He L, Tian J, Liang C-S, Chen X, et al. Development and Validation of a Radiomics Nomogram for Preoperative Prediction of Lymph Node Metastasis in Colorectal Cancer. J Clin Oncol. 2016;34(18):2157-64.

26. Reiners C. Thyroid cancer in 2013: Advances in our understanding of differentiated thyroid cancer. Nat Rev Endocrinol. 2014;10(2):69-70.

27. Haddad RI, Lydiatt WM, Ball DW, Busaidy NL, Byrd D, Callender G, et al. Anaplastic Thyroid Carcinoma, Version 2.2015. J Natl Compr Canc Netw. 2015;13(9):1140-50.

28. Hwang SH, Kim E-K, Moon HJ, Yoon JH, Kwak JY. Risk of Thyroid Cancer in Euthyroid Asymptomatic Patients with Thyroid Nodules with an Emphasis on Family History of Thyroid Cancer. Korean J Radiol. 2016;17(2):255-63.

29. Lapteva N, Huang XF. CCL5 as an adjuvant for cancer immunotherapy. Expert opinion on biological therapy. 2010;10(5):725-33.

30. Zhang LJ, Xiong Y, Nilubol N, He M, Bommareddi S, Zhu X, et al. Testosterone regulates thyroid cancer progression by modifying tumor suppressor genes and tumor immunity. Carcinogenesis. 2015;36(4):420-8.

31. Rago T, Fiore E, Scutari M, Santini F, Di Coscio G, Romani R, et al. Male sex, single nodularity, and young age are associated with the risk of finding a papillary thyroid cancer on fine-needle aspiration cytology in a large series of patients with nodular thyroid disease. European journal of endocrinology. 2010;162(4):763-70.

32. Belfiore A, La Rosa GL, La Porta GA, Giuffrida D, Milazzo G, Lupo L, et al. Cancer risk in patients with cold thyroid nodules: relevance of iodine intake, sex, age, and multinodularity. The American journal of medicine. 1992;93(4):363-9.

33. Tuttle RM, Lemar H, Burch HB. Clinical features associated with an increased risk of thyroid malignancy in patients with follicular neoplasia by fine-needle aspiration. Thyroid. 1998;8(5):377-83.

34. Hollowell JG, Staehling NW, Flanders WD, Hannon WH, Gunter EW, Spencer CA, et al. Serum TSH, T(4), and thyroid antibodies in the United States population (1988 to 1994): National Health and Nutrition Examination Survey (NHANES III). J Clin Endocrinol Metab. 2002;87(2):489-99.

35. Haymart MR, Repplinger DJ, Leverson GE, Elson DF, Sippel RS, Jaume JC, et al. Higher serum thyroid stimulating hormone level in thyroid nodule patients is associated with greater risks of differentiated thyroid cancer and advanced tumor stage. J Clin Endocrinol Metab. 2008;93(3):809-14. 
36. Du Villard JA, Wicker R, Crespo P, Russo D, Filetti S, Gutkind JS, et al. Role of the cAMP and MAPK pathways in the transformation of mouse 3 T3 fibroblasts by a TSHR gene constitutively activated by point mutation. Oncogene. 2000;19(42):4896-905.

37. Haymart MR. Understanding the relationship between age and thyroid cancer. Oncologist. 2009;14(3):216-21.

38. Tuttle RM, Haugen B, Perrier ND. Updated American Joint Committee on Cancer/Tumor-NodeMetastasis Staging System for Differentiated and Anaplastic Thyroid Cancer (Eighth Edition): What Changed and Why? Thyroid. 2017;27(6):751-6.

39. Rao SN, Zafereo M, Dadu R, Busaidy NL, Hess K, Cote GJ, et al. Patterns of Treatment Failure in Anaplastic Thyroid Carcinoma. Thyroid. 2017;27(5):672-81.

40. Patell R, Mikhael A, Tabet M, Bena J, Berber E, Nasr C. Assessing the utility of preoperative serum thyroglobulin in differentiated thyroid cancer: a retrospective cohort study. Endocrine. 2018;61(3):50610.

41. Van Calster B, Wynants L, Verbeek JFM, Verbakel JY, Christodoulou E, Vickers AJ, et al. Reporting and Interpreting Decision Curve Analysis: A Guide for Investigators. European urology. 2018;74(6):796804.

\section{Tables}


Table 1. Description of study population.

\begin{tabular}{|c|c|c|c|}
\hline & Male & Female & Total \\
\hline Gender & 32,783 (24.29\%) & $102,179(75.71 \%)$ & $134,962(100 \%)$ \\
\hline \multicolumn{4}{|l|}{ Age } \\
\hline G1(<55years old $)$ & 16,328 (49.81\%) & 65,161 (63.77\%) & $81,489(60.38 \%)$ \\
\hline G2( $\geqq 55$ years old $)$ & 16,455 (50.19\%) & 37,018 (36.23\%) & $53,473(39.62 \%)$ \\
\hline \multicolumn{4}{|l|}{ Histology Type } \\
\hline PTC & 27,214 (88.07\%) & $90,593(92.28 \%)$ & 117,807 (91.27\%) \\
\hline FTC & 2,089 ( 6.76\%) & 4,975 ( 5.07\%) & $7,064(5.47 \%)$ \\
\hline MTC & $1,180(3.82 \%)$ & $1,926$ ( $1.96 \%)$ & $3,106(2.41 \%)$ \\
\hline ATC & 418 ( $1.35 \%)$ & $677(0.69 \%)$ & $1,095(0.85 \%)$ \\
\hline N/A & & & $5,890(\mathrm{~N} / \mathrm{A})$ \\
\hline \multicolumn{4}{|l|}{ T-stage } \\
\hline T1a & $8,322(27.92 \%)$ & 36,004 (37.92\%) & $44,326(35.53 \%)$ \\
\hline T1b & $5,847(19.61 \%)$ & $22,292(23.48 \%)$ & 28,139 (22.55\%) \\
\hline $\mathrm{T} 2$ & $5,670(19.02 \%)$ & 16,283 (17.15\%) & 21,953 (17.60\%) \\
\hline ТЗа & $3,316(11.12 \%)$ & $5,279(5.56 \%)$ & $8,595(6.89 \%)$ \\
\hline T3b & $2,421(8.12 \%)$ & $6,260(6.59 \%)$ & $8,681(6.96 \%)$ \\
\hline T4a & $3,414(11.45 \%)$ & $7,409$ ( $7.80 \%)$ & $10,823(8.67 \%)$ \\
\hline T4b & $821(2.75 \%)$ & $1,430(1.51 \%)$ & $2,251(1.80 \%)$ \\
\hline N/A & & & $10,194(\mathrm{~N} / \mathrm{A})$ \\
\hline \multicolumn{4}{|l|}{$\mathrm{N}$-stage } \\
\hline NOa & $6,870(23.04 \%)$ & $30,506(32.05 \%)$ & 37,376 (29.90\%) \\
\hline NOb & 14,678 (49.22\%) & $48,260(50.70 \%)$ & 62,938 (50.35\%) \\
\hline N1a & 4,692 (15.73\%) & 11,027 (11.58\%) & 15,719 (12.57\%) \\
\hline N1b & $3,581(12.01 \%)$ & $5,393(5.67 \%)$ & $8,974(7.18 \%)$ \\
\hline N/A & & & $9,955(\mathrm{~N} / \mathrm{A})$ \\
\hline \multicolumn{4}{|l|}{ M-stage } \\
\hline MO & 30,317 (95.47\%) & $97,679(98.23 \%)$ & 127,996 (97.56\%) \\
\hline
\end{tabular}




\begin{tabular}{|c|c|c|c|}
\hline M1 & $1,437(4.53 \%)$ & $1,762(1.77 \%)$ & $3,199(2.44 \%)$ \\
\hline N/A & & & 3,767 (N/A) \\
\hline \multicolumn{4}{|c|}{ Chemotherapy } \\
\hline $\mathrm{N} / \mathrm{U}$ & $32,171(98.13 \%)$ & $101,436(99.27 \%)$ & 133,607 (99.00\%) \\
\hline Yes & $612(1.87 \%)$ & 743 (0.73\%) & $1,355(1.00 \%)$ \\
\hline \multicolumn{4}{|c|}{${ }^{131}$ | therapy } \\
\hline$N / U$ & $15,974(52.00 \%)$ & $54,841(55.76 \%)$ & 70,815 (54.87\%) \\
\hline Yes & $14,745(48.00 \%)$ & $43,505(44.24 \%)$ & $58,250(45.13 \%)$ \\
\hline $\mathrm{N} / \mathrm{A}$ & & & $5,897(\mathrm{~N} / \mathrm{A})$ \\
\hline \multicolumn{4}{|c|}{ Surgical Method } \\
\hline LO & $2,148(7.75 \%)$ & 7,205 (8.03\%) & $9,353(7.96 \%)$ \\
\hline $\mathrm{S} / \mathrm{N} T$ & $1,020(3.68 \%)$ & $3,266(3.64 \%)$ & $4,286(3.65 \%)$ \\
\hline TT & $24,535(88.56 \%)$ & 79,295 (88.34\%) & $103,830(88.39 \%)$ \\
\hline $\mathrm{N} / \mathrm{A}$ & & & $17,493(\mathrm{~N} / \mathrm{A})$ \\
\hline \multicolumn{4}{|c|}{$\begin{array}{l}\text { G1, Group 1; G2, Group 2; N/A, Not Applicable; N/U, No/Unknown; LO, Lobectomy ONLY; S/N T, } \\
\text { Subtotal or near total thyroidectomy; TT, Total thyroidectomy; }\end{array}$} \\
\hline
\end{tabular}


Table 2. Univariate analysis.

$\begin{array}{llllll}\text { Coef } & \underset{\text { (Coef) }}{\mathrm{SE}} \mathrm{HR} & \mathrm{HR}(95 \% \mathrm{Cl}) & \text { P value } & \text { Events } & \text { MST }\end{array}$

Lower Upper

(blank/s=NR)

Gender

( $\mathrm{R}=$ Male)

$<0.0001 \quad 1,487$

Female

$-0.96 \quad 0.03$

$0.38 \quad 0.36$

0.41

2,010

Age $(\mathrm{R}=\mathrm{G} 1)$

$\begin{array}{lllll}2.36 & 0.05 & 10.55 & 9.66 & 11.53\end{array}$

586

G2

Histology

Type (R=PTC)

1,435

\begin{tabular}{llllll} 
FTC & 1.06 & 0.07 & 2.88 & 2.52 & 3.29 \\
MTC & 2.45 & 0.06 & 11.60 & 10.33 & 13.04 \\
\hline ATC & 5.47 & 0.05 & 237.99 & 216.38 & 261.75
\end{tabular}

T-stage

( $\mathrm{R}=\mathrm{T} 1 \mathrm{a})$

$\mathrm{T} 1 \mathrm{~b}$

0.58

0.13

1.79

1.38

2.32

105

T2

1.38

0.12

3.98

3.15

5.02

T3a

2.67

0.11

14.46

11.57

18.06

$8.04 \quad 12.89$

10.18

8.04

44.20

$\mathrm{T} 4 \mathrm{a}$

3.59

0.10

36.12

29.5

286.23

$\mathrm{T} 4 \mathrm{~b}$

5.4

0.10

233.66

$190.75 \quad 286.23$

$\mathrm{N}$-stage

$(\mathrm{R}=\mathrm{NOa})$

\begin{tabular}{llllll} 
N0b & 0.72 & 0.07 & 2.06 & 1.81 & 2.35 \\
\hline N1a & 1.60 & 0.07 & 4.97 & 4.32 & 5.72 \\
\hline N1b & 2.47 & 0.07 & 11.87 & 10.36 & 13.60
\end{tabular}

M-stage

$(\mathrm{R}=\mathrm{M} 0)$

M1

$4.08 \quad 0.04$

58.97

54.94

63.29

1,786

$1,406 \quad 28$ 


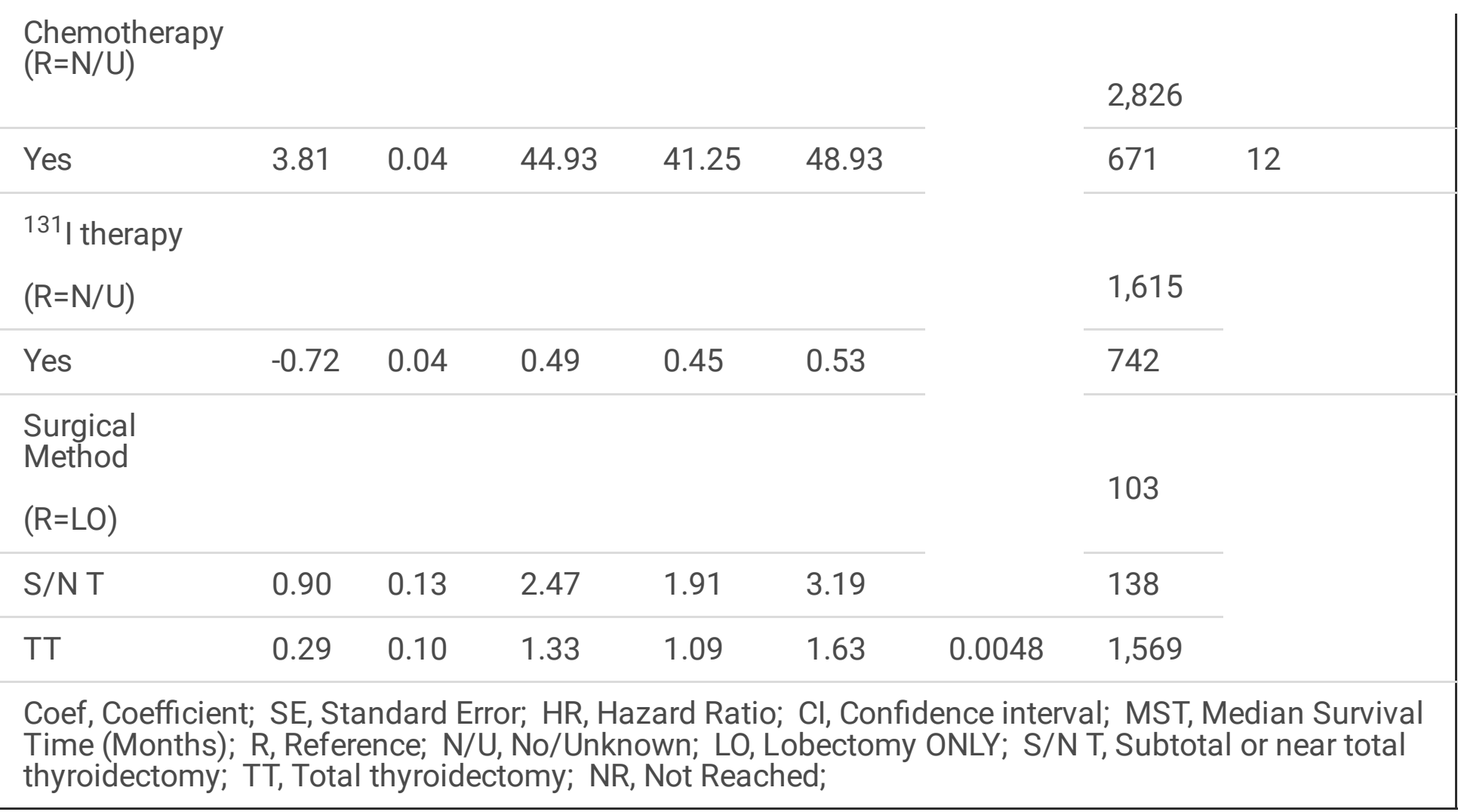


Table 3. Multivariate analysis and comparison of three COX models.

$\begin{array}{llll}\text { Coef } & \text { SE (Coef) HR }(95 \% \mathrm{Cl}) & \text { P value } \\ & & \text { Lower Upper }\end{array}$

Gender ( $\mathrm{R}=\mathrm{M})$

Female

Model 1

$-0.32 \quad 0.07$

0.73

0.63

0.84

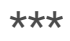

Model 2

$-0.26 \quad 0.06$

$0.77 \quad 0.68$

0.87

Model 3

$-0.27 \quad 0.06$

0.77

0.68

0.87

$\star \star \star$

Age $(\mathrm{R}=\mathrm{G} 1)$

G2

Model 1

$2.04 \quad 0.09$

7.72

6.53

9.13

7.63

6.54

8.91

Model 2

2.03

0.08

7.64

6.54

8.92

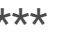

Histology Type (R=PTC)

FTC

\begin{tabular}{|c|c|c|c|c|c|c|c|}
\hline Model 1 & & 0.55 & 0.13 & 1.72 & 1.35 & 2.21 & $\star \star \star *$ \\
\hline Model 2 & & 0.44 & 0.11 & 1.55 & 1.24 & 1.94 & $\star \star$ \\
\hline Model 3 & & 0.44 & 0.11 & 1.55 & 1.24 & 1.94 & $\star *$ \\
\hline \multicolumn{8}{|l|}{ MTC } \\
\hline Model 1 & & 0.61 & 0.15 & 1.84 & 1.37 & 2.48 & $* \star \star$ \\
\hline Model 2 & & 0.61 & 0.13 & 1.84 & 1.43 & 2.36 & $* * \star$ \\
\hline Model 3 & & 0.63 & 0.13 & 1.87 & 1.46 & 2.40 & $\star \star \star *$ \\
\hline \multicolumn{8}{|l|}{ ATC } \\
\hline Model 1 & & 2.79 & 0.20 & 16.35 & 11.14 & 23.99 & $\star \star \star$ \\
\hline Model 2 & & 2.77 & 0.14 & 15.96 & 12.07 & 21.09 & $\star \star \star *$ \\
\hline Model 3 & & 2.82 & 0.13 & 16.83 & 12.92 & 21.92 & 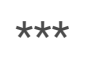 \\
\hline T-stage & $(\mathrm{R}=\mathrm{T} 1 \mathrm{a})$ & & & & & & \\
\hline \multicolumn{8}{|l|}{$\mathrm{T} 1 \mathrm{~b}$} \\
\hline Model 1 & & 0.34 & 0.18 & 1.40 & 0.98 & 1.99 & 0.06 \\
\hline
\end{tabular}




\begin{tabular}{|c|c|c|c|c|c|c|}
\hline Model 2 & 0.61 & 0.16 & 1.85 & 1.34 & 2.53 & $\star \star$ \\
\hline Model 3 & 0.61 & 0.16 & 1.85 & 1.35 & 2.54 & ** \\
\hline \multicolumn{7}{|l|}{ T2 } \\
\hline Model 1 & 1.03 & 0.16 & 2.80 & 2.04 & 3.85 & $\star \star \star$ \\
\hline Model 2 & 1.26 & 0.15 & 3.52 & 2.63 & 4.70 & 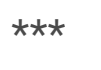 \\
\hline Model 3 & 1.26 & 0.15 & 3.51 & 2.63 & 4.69 & $\star \star \star *$ \\
\hline \multicolumn{7}{|l|}{ Т3a } \\
\hline Model 1 & 1.67 & 0.17 & 5.33 & 3.82 & 7.43 & $\star \star \star *$ \\
\hline Model 2 & 1.95 & 0.15 & 7.00 & 5.19 & 9.45 & $\star \star \star *$ \\
\hline Model 3 & 1.94 & 0.15 & 6.98 & 5.17 & 9.43 & 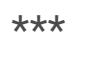 \\
\hline \multicolumn{7}{|l|}{ T3b } \\
\hline Model 1 & 1.88 & 0.16 & 6.55 & 4.76 & 9.00 & $\star \star \star ~$ \\
\hline Model 2 & 2.07 & 0.15 & 7.91 & 5.87 & 10.65 & $\star \star \star *$ \\
\hline Model 3 & 2.07 & 0.15 & 7.91 & 5.87 & 10.65 & $\star \star * *$ \\
\hline \multicolumn{7}{|l|}{ T4a } \\
\hline Model 1 & 2.44 & 0.14 & 11.45 & 8.63 & 15.20 & $\star \star \star$ \\
\hline Model 2 & 2.71 & 0.13 & 14.98 & 11.53 & 19.45 & $\star \star \star \star$ \\
\hline Model 3 & 2.71 & 0.13 & 15.00 & 11.55 & 19.48 & $\star \star \star \star$ \\
\hline \multicolumn{7}{|l|}{ T4b } \\
\hline Model 1 & 3.04 & 0.17 & 20.99 & 15.01 & 29.36 & $\star \star \star$ \\
\hline Model 2 & 3.26 & 0.15 & 26.07 & 19.28 & 35.24 & $\star \star \star$ \\
\hline Model 3 & 3.27 & 0.15 & 26.36 & 19.51 & 35.61 & $\star \star \star *$ \\
\hline \multicolumn{7}{|c|}{$\mathrm{N}$-stage $(\mathrm{R}=\mathrm{NOa})$} \\
\hline \multicolumn{7}{|l|}{ NOb } \\
\hline Model 1 & 0.23 & 0.11 & 1.26 & 1.02 & 1.56 & 0.03 \\
\hline Model 2 & 0.43 & 0.10 & 1.54 & 1.27 & 1.87 & $\star \star \star \star$ \\
\hline Model 3 & 0.43 & 0.10 & 1.53 & 1.26 & 1.85 & $\star \star \star \star$ \\
\hline \multicolumn{7}{|l|}{ N1a } \\
\hline Model 1 & 0.87 & 0.11 & 2.38 & 1.90 & 2.97 & $\star \star \star ~$ \\
\hline Model 2 & 0.92 & 0.11 & 2.50 & 2.03 & 3.09 & $\star \star \star$ \\
\hline
\end{tabular}




\begin{tabular}{|c|c|c|c|c|c|c|}
\hline Model 3 & 0.91 & 0.11 & 2.48 & 2.01 & 3.05 & $\star \star \star \star ~$ \\
\hline \multicolumn{7}{|l|}{ N1b } \\
\hline Model 1 & 1.06 & 0.12 & 2.88 & 2.30 & 3.62 & $\star \star \star \star ~$ \\
\hline Model 2 & 1.11 & 0.11 & 3.04 & 2.46 & 3.76 & $\star \star \star \star ~$ \\
\hline Model 3 & 1.11 & 0.11 & 3.03 & 2.45 & 3.75 & $\star \star \star \star ~$ \\
\hline \multicolumn{7}{|c|}{ M-stage $(\mathrm{R}=\mathrm{M} 0)$} \\
\hline \multicolumn{7}{|l|}{ M1 } \\
\hline Model 1 & 2.14 & 0.09 & 8.50 & 7.11 & 10.16 & $\star \star \star \star ~$ \\
\hline Model 2 & 2.13 & 0.08 & 8.42 & 7.17 & 9.90 & $\star \star \star \star ~$ \\
\hline Model 3 & 2.14 & 0.08 & 8.46 & 7.20 & 9.94 & $\star \star \star \star$ \\
\hline \multicolumn{7}{|c|}{ Chemotherapy $(\mathrm{R}=\mathrm{N} / \mathrm{U})$} \\
\hline \multicolumn{7}{|l|}{ Yes } \\
\hline Model 1 & 0.37 & 0.18 & 1.45 & 1.01 & 2.09 & 0.04 \\
\hline Model 2 & 0.17 & 0.14 & 1.18 & 0.90 & 1.55 & 0.23 \\
\hline Model 3 & $\mathrm{~N} / \mathrm{A}$ & $\mathrm{N} / \mathrm{A}$ & $\mathrm{N} / \mathrm{A}$ & $\mathrm{N} / \mathrm{A}$ & $\mathrm{N} / \mathrm{A}$ & $\mathrm{N} / \mathrm{A}$ \\
\hline \multicolumn{7}{|c|}{${ }^{131}$ I therapy $(\mathrm{R}=\mathrm{N} / \mathrm{U})$} \\
\hline \multicolumn{7}{|l|}{ Yes } \\
\hline Model 1 & -0.27 & 0.08 & 0.76 & 0.65 & 0.89 & $\star \star *$ \\
\hline Model 2 & -0.46 & 0.07 & 0.63 & 0.55 & 0.73 & $\star \star \star \star ~$ \\
\hline Model 3 & -0.46 & 0.07 & 0.63 & 0.55 & 0.73 & $\star \star \star \star ~$ \\
\hline \multicolumn{7}{|c|}{ Surgical Method (R=LO) } \\
\hline \multicolumn{7}{|l|}{$\mathrm{S} / \mathrm{N} \mathrm{T}$} \\
\hline Model 1 & 0.27 & 0.23 & 1.31 & 0.84 & 2.05 & 0.24 \\
\hline Model 2 & N/A & N/A & $\mathrm{N} / \mathrm{A}$ & $\mathrm{N} / \mathrm{A}$ & $\mathrm{N} / \mathrm{A}$ & N/A \\
\hline Model 3 & $\mathrm{~N} / \mathrm{A}$ & N/A & $\mathrm{N} / \mathrm{A}$ & N/A & $\mathrm{N} / \mathrm{A}$ & N/A \\
\hline \multicolumn{7}{|l|}{ TT } \\
\hline Model 1 & 0.02 & 0.17 & 1.02 & 0.74 & 1.42 & 0.89 \\
\hline Model 2 & $\mathrm{~N} / \mathrm{A}$ & N/A & $\mathrm{N} / \mathrm{A}$ & $\mathrm{N} / \mathrm{A}$ & $\mathrm{N} / \mathrm{A}$ & N/A \\
\hline Model 3 & $\mathrm{~N} / \mathrm{A}$ & $\mathrm{N} / \mathrm{A}$ & $\mathrm{N} / \mathrm{A}$ & N/A & $\mathrm{N} / \mathrm{A}$ & $\mathrm{N} / \mathrm{A}$ \\
\hline
\end{tabular}


Coef, Coefficient; SE, Standard Error; HR, Hazard Ratio; Cl, Confidence interval; R, Reference; M, Male; G1, Group1; G2, Group 2; N/U, No/Unknown; LO, Lobectomy ONLY; S/N T, Subtotal or near total thyroidectomy; TT, Total thyroidectomy; N/A, Not Applicable; $* \star,=0.0001 ;{ }^{\star \star \star},<0.0001$;

\begin{tabular}{|c|c|c|c|c|c|c|c|}
\hline & \multirow{2}{*}{$\begin{array}{l}\text { Predicted time } \\
\text { (months) }\end{array}$} & \multirow[t]{2}{*}{ Sensitivity } & \multirow[t]{2}{*}{ Specificity } & \multirow[t]{2}{*}{ AUC } & \multirow{2}{*}{$\begin{array}{l}\text { Harrell's } \\
\text { C-index }\end{array}$} & \multicolumn{2}{|c|}{ C-index $(95 \% \mathrm{Cl})$} \\
\hline & & & & & & Lower & Upper \\
\hline \multirow{3}{*}{$\begin{array}{l}\text { Training } \\
\text { set }\end{array}$} & 12 & 0.8895 & 0.8984 & 0.9562 & \multirow[t]{3}{*}{0.9450} & \multirow{3}{*}{0.9378} & \multirow[t]{3}{*}{0.9522} \\
\hline & 36 & 0.8537 & 0.8502 & 0.9273 & & & \\
\hline & 60 & 0.8265 & 0.8222 & 0.9009 & & & \\
\hline \multirow{3}{*}{$\begin{array}{l}\text { Validation } \\
\text { set }\end{array}$} & 12 & 0.9284 & 0.8771 & 0.9645 & \multirow{3}{*}{0.9421} & \multirow{3}{*}{0.9314} & \multirow[t]{3}{*}{0.9528} \\
\hline & 36 & 0.8585 & 0.8778 & 0.9329 & & & \\
\hline & 60 & 0.7662 & 0.8526 & 0.8894 & & & \\
\hline
\end{tabular}

\section{Figures}




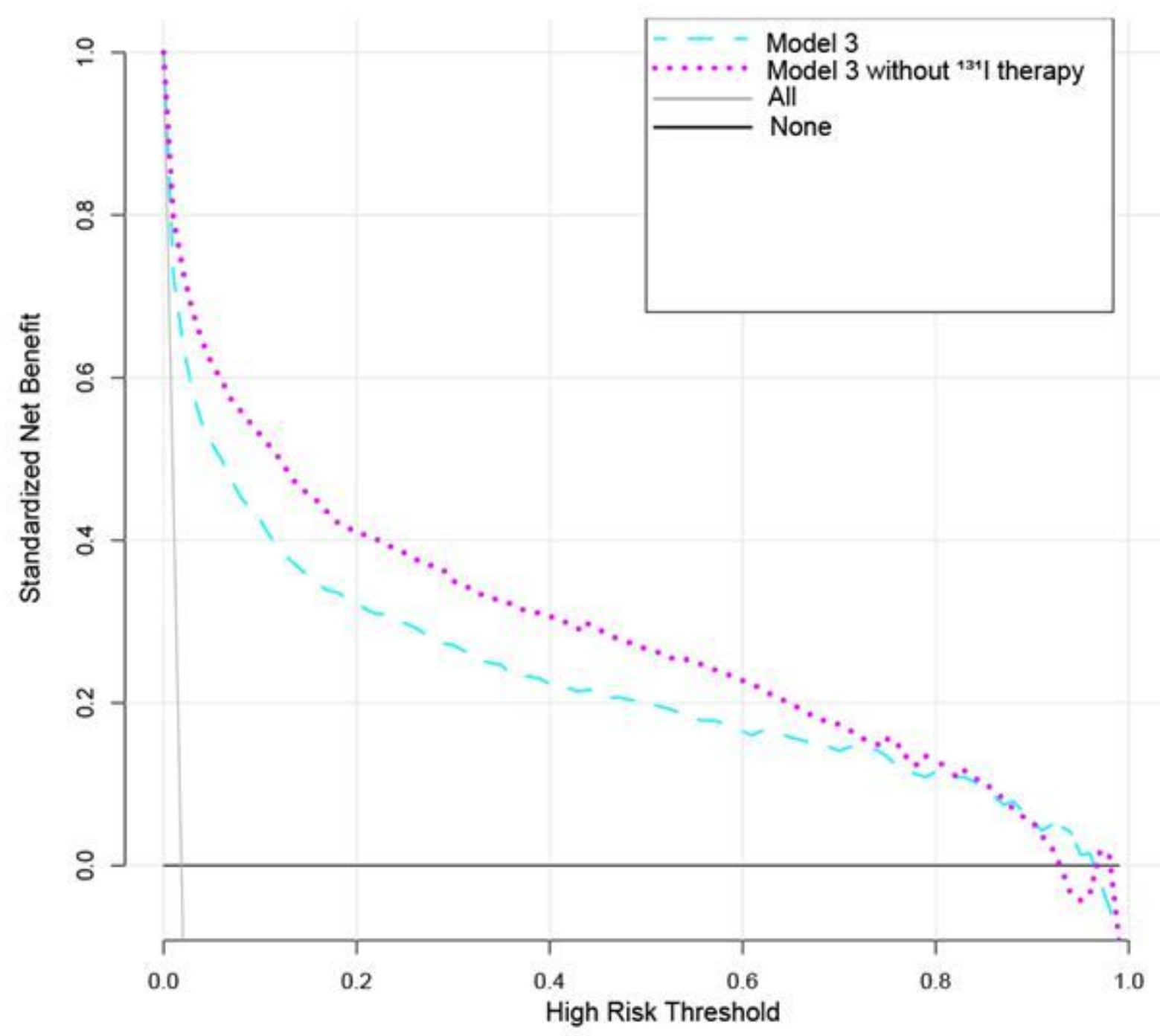

Figure 1

Comparison of DCA between Model 3 and Model 3 without 131I therapy. X-axis stands for threshold probability. When the diagnostic method reaches a certain value, the probability of a certain event of patient $\mathrm{i}$ is denoted as $\mathrm{Pi}$; When $\mathrm{Pi}$ reaches a certain threshold (denoted as $\mathrm{Pt}$ ), it is defined as positive. Yaxis stands for standardized net benefit after the advantage minus the disadvantage. Net benefit is calculated by removing those false positive patients from true positive patients and then weighted by the evaluation between the disadvantage of giving up treatment and the negative influence of unnecessary treatment(41). The black horizontal line indicates that all samples are negative $(\mathrm{Pi}<\mathrm{Pt})$, which means none of the patients received intervention and the net benefit is 0 ; The gray oblique line indicates that all samples are positive and all patients received intervention. 


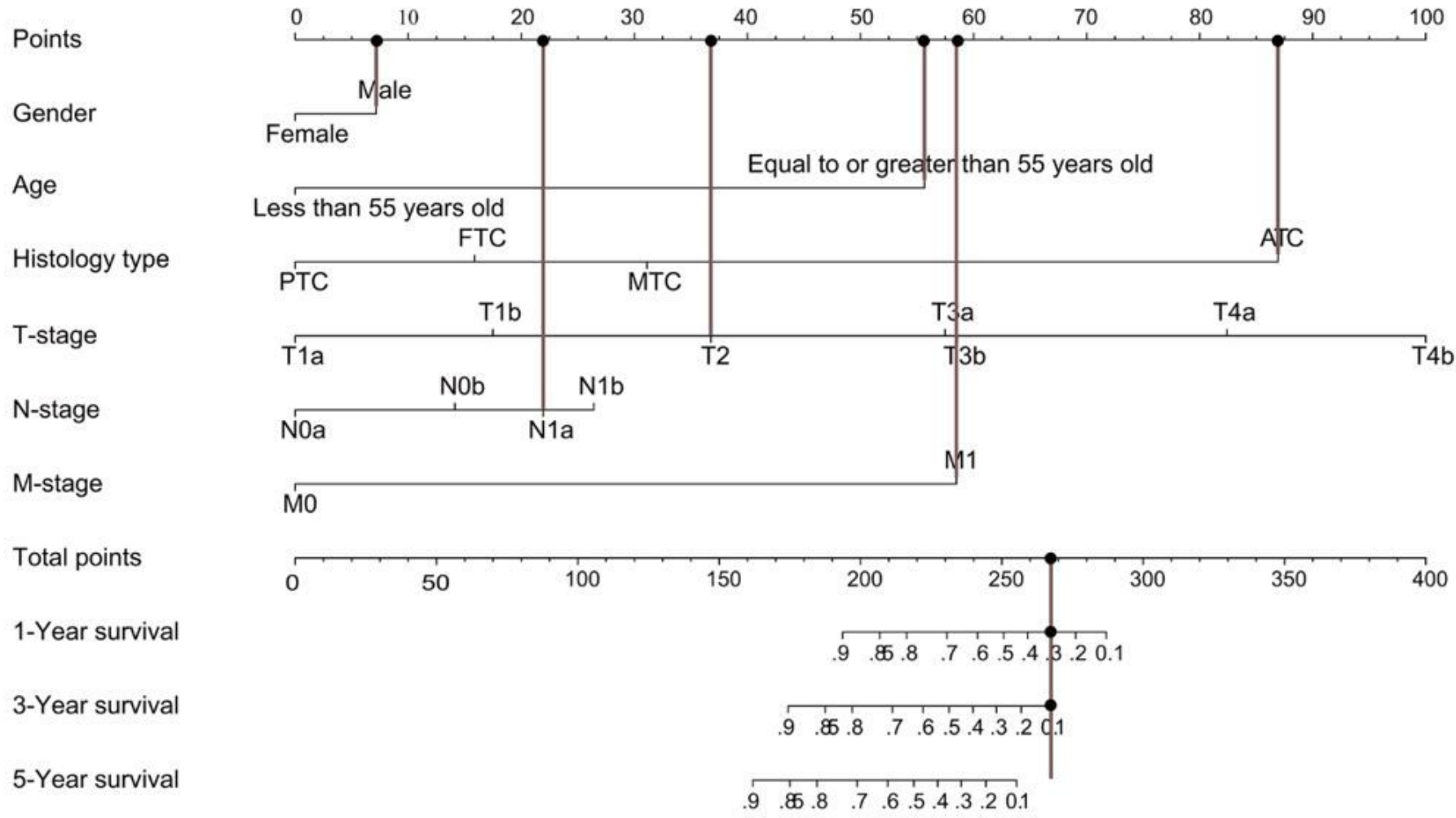

\section{Figure 2}

A nomogram with gender, age, histology type, T-stage, $\mathrm{N}$-stage and $\mathrm{M}$-stage predicting the survival probability of 1-year, 3-year and 5-year time point in thyroid carcinoma. Vertical lines show a predictive example: Supposing a male patient (8 points) aged 57 (56 points) diagnosed with ATC (87 points) at T2 (37 points), N1a (22 points) and M1 (59 points) stages, his total points (269) can be projected to 1-year, 3year and 5-year survival axis and his survival probabilities are $30 \%, 10 \%$ and $<10 \%$ respectively. 

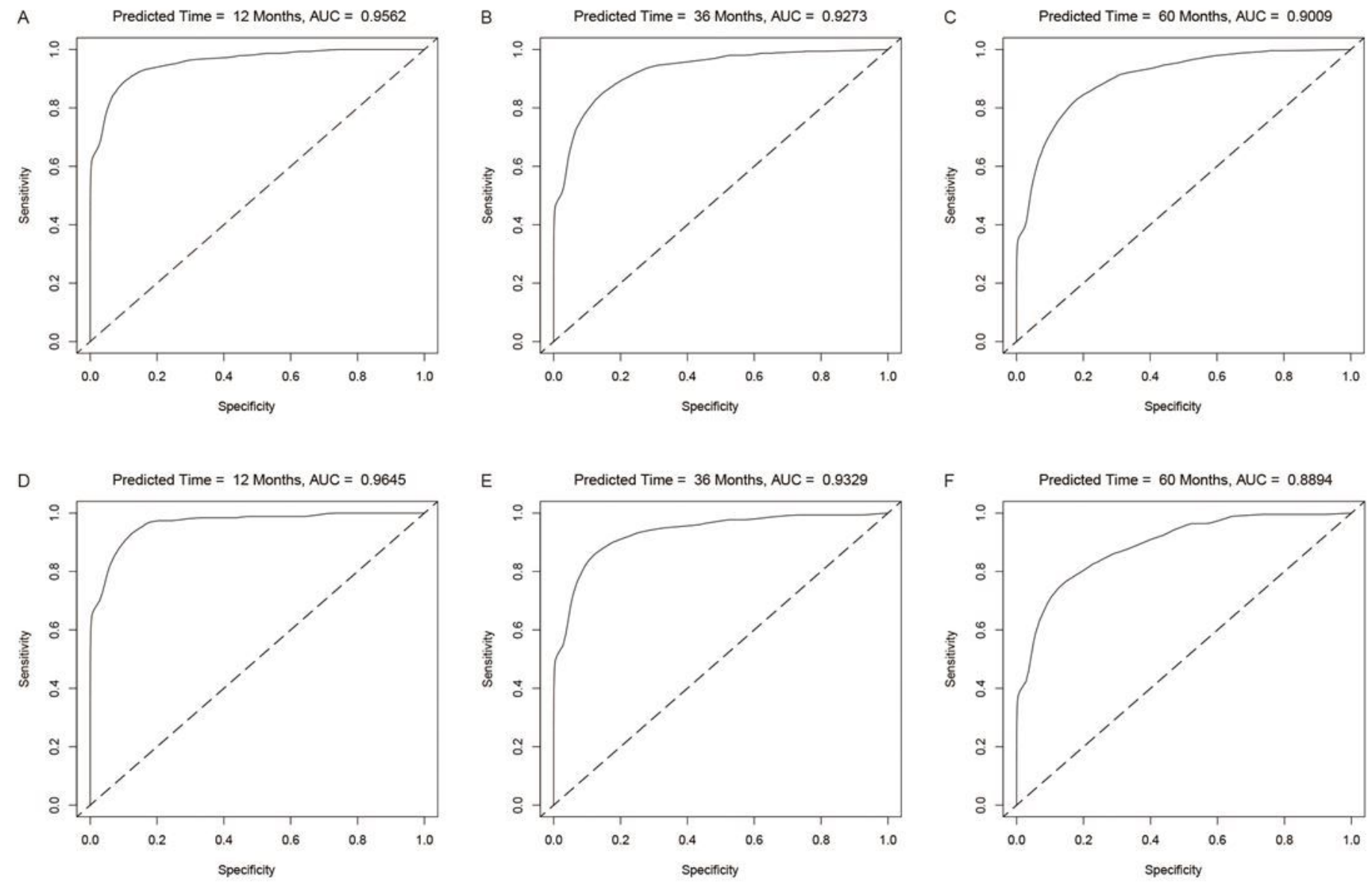

\section{Figure 3}

Time-dependent ROC of training set and validation set. $a, b$ and c, Training set. $d$, e and $f$, Validation set. Method $=$ NNE (Nearest Neighbor Estimation). Bootstrap $=500$. Sensitivity (True Positive Rate) $=$ "True Positive" /"Ture Positive + False Negative" "×100\%" . Specificity (Ture Negative Rate) = "True Negative" /"Ture Negative + False Positive" "×100\%" . 
A

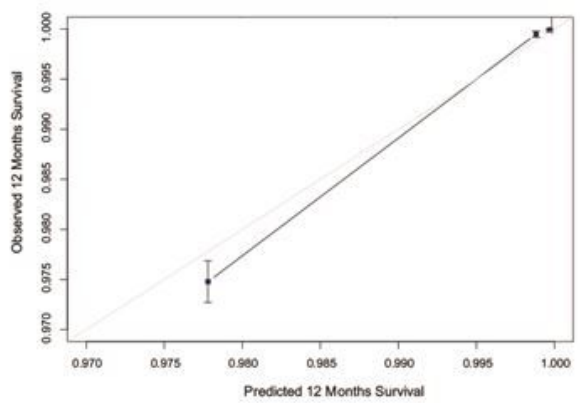

D

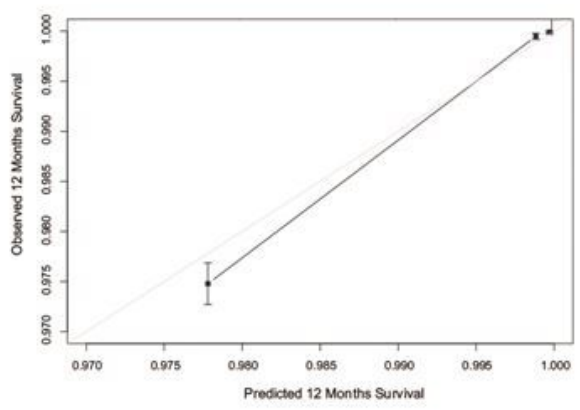

B

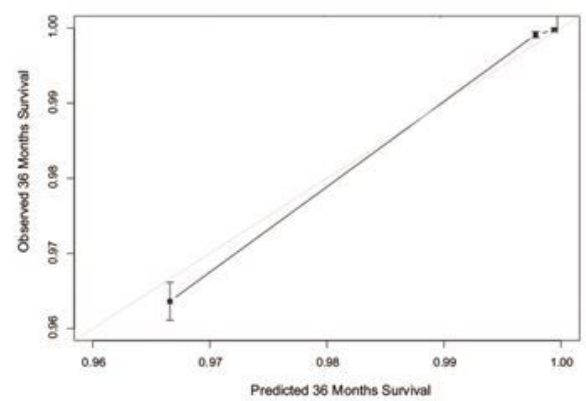

$E$

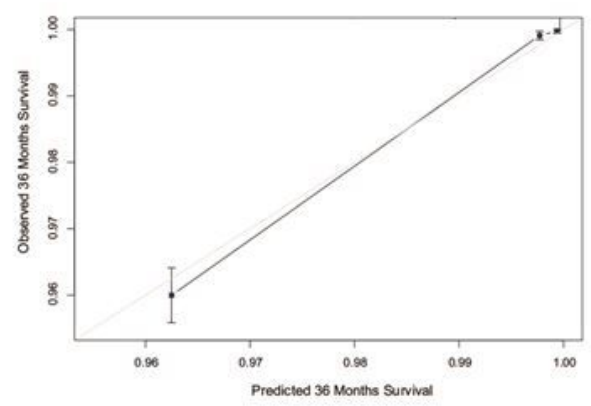

c

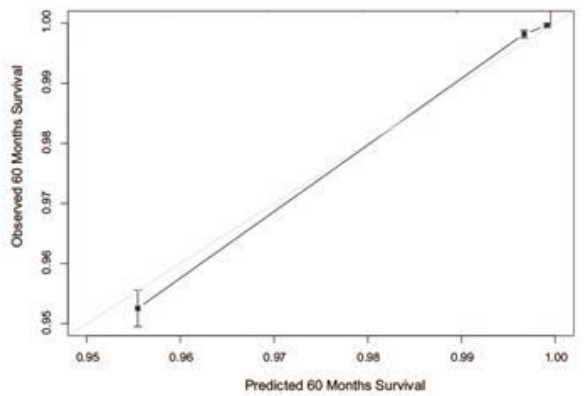

$\mathrm{F}$

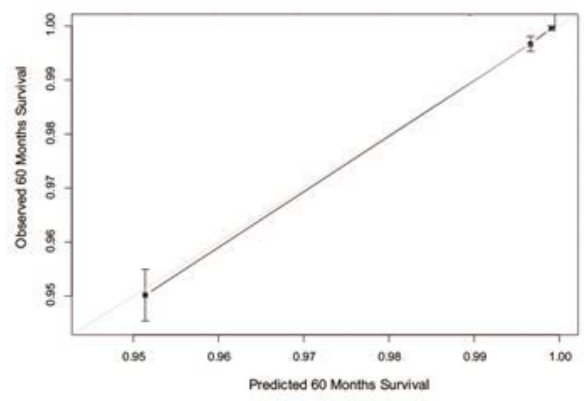

\section{Figure 4}

Calibration plot of training set and validation set. a, b and c, Training set. $d$, e and f, Validation set. Bootstrap $=500$. X-axis, Predicted survival probability. Y-axis, Observed survival probability. Line segment at two side of intersection, $95 \% \mathrm{Cl}$ of survival probability. Gray line, Ideal (Predicted coincides exactly with observed). Black line twisting around the gray line, Difference between predicted and observed. 